\title{
VIVÊNCIAS DE PACIENTES FRENTE À TROCA DE ESTAGIÁRIOS/TERAPEUTAS EM UMA CLÍNICA-ESCOLA
}

DOI: $10.48075 /$ RI.V22I2.24987

\author{
Thiago Ribeiro Moreira ${ }^{1}$ \\ Myriam Siqueira da Cunha ${ }^{2}$
}

RESUMO: A troca do terapeuta durante a psicoterapia incide diretamente na aliança de trabalho, porém, poucos estudos explicam a forma como pacientes vivem essa experiência e sua influência no processo psicoterápico. É preciso considerar as características institucionais dos serviços que convivem com a transitoriedade de terapeutas, como as clínicas-escola com estagiários/terapeutas. Este estudo buscou compreender a vivência de pacientes e os significados atribuídos à experiência de troca de estagiários/terapeutas de Psicologia em uma clínica-escola do sul do Brasil. Foram ${ }^{1}$ investigados dois participantes escolhidos por sorteio, após indicação da coordenação da clínica-escola de pacientes que vivenciaram, no mínimo uma vez, nos últimos dois anos, a troca de estagiário/terapeuta. O instrumento para a coleta de dados foi a entrevista em profundidade (SEIDMAN, 2019). As entrevistas foram transcritas e, concomitantemente, começou-se a análise e interpretação, fundamentadas na técnica de isolamento temático de Van Manen (2018). A partir das unidades de significado reveladas, foi possível extrair a estrutura da experiência vivida. Nesse processo, emergiram duas unidades de significado: características do estagiário/terapeuta e aliança empática, que são a estrutura do tema fenomenológico: o paciente como sujeito no processo psicoterápico. Esse tema representa a essência do fenômeno vivido, em relação à troca do estagiário/terapeuta.

Palavras-chave: Processos psicoterapêuticos; Psicologia clínica; Aliança terapêutica.

\section{EXPERIENCE OF PATIENTS TOWARDS THE EXCHANGE OF INTERNS/THERAPISTS IN A SCHOOL-CLINIC}

ABSTRACT: The exchange of the therapist during the psychotherapy, will incur directly in the work alliance, but, a few studies explain the manner how patients live this experience and its influence in the psychotherapeutic process. Seen in these terms, it is needed to consider the institutional characteristics of the services that coexist with the temporariness of therapists, as the case of the school-clinics with the interns/therapists. This study sought, so, to comprehend the living of patients and the assigned meanings to the exchange of Psychology interns/therapists experience in a South

\footnotetext{
${ }^{1}$ Graduado em Biblioteconomia e Psicologia, mestre em Ciências da Saúde, bolsista de pesquisa da Universidade Federal de Pelotas, Departamento de Medicina Social (UFPel/DMS). E-mail: thiagoribmor@yahoo.com.br

${ }^{2}$ Graduada em Filosofia e Direito, doutora em Engenharia de Produção, docente do Instituto Federal de Educação, Ciência e Tecnologia Sul-rio-grandense, campus Visconde da Graça (IFSUL/CaVG), Pelotas/RS. E-mail: mscpel@gmail.com
} 
Brazil school-clinic, during the therapeutic process. Two participants chosen by drawn lot were investigated, after indication of the school-clinic coordination of patients who embraced the inclusion criteria, in other words, who had lived, at least once, in the last two years, the exchange of interns/therapist. The utilized instrument to the collect of the inputs was the depth interview (SEIDMAN, 2019). The interviews were transcribed and, concomitantly, the analysis and interpretation began, all founded in the thematic isolation technic of Van Manen (2018). From meaning unities revealed, it was possible to extract the structure of their lived experience. In this process, two meaning unities emerged: characteristics of the interns/therapist and empathetic alliance, which are the structure of the phenomenological theme: the patient as a subject in the psychotherapeutic process. This theme represents the essence of the lived phenomenon in relation to the exchange of the interns/therapist.

Key words: Psychotherapeutic processes; Psychology clinical; Therapeutic alliance.

\section{INTRODUÇÃO}

O atendimento psicológico em clínica-escola de psicologia é realizado por estagiários que estão nos últimos semestres da graduação, supervisionados por docentes do curso. Sendo assim, muitas vezes, ocorre a troca em razão do término do período de estágio obrigatório, causando descontinuidade no atendimento psicoterápico.

O estágio se caracteriza por ser atividade de aprendizagem em ambiente de trabalho, tendo como objetivo a preparação para profissionalização (BRASIL, 2008), proporcionando ao estudante/estagiário os primeiros contatos com a prática profissional e o campo de atuação (SANTOS; NÓBREGA, 2017). Dessa forma, nesse tempo e lugar, há intersecção entre o papel de estudante/estagiário e profissional/terapeuta (SILVA; COELHO; PONTES, 2019).

Assim, por ser a clínica-escola espaço que se estrutura a identidade profissional do estudante e se consolida os distanciamentos entre o saber constituído e o que se constrói, optou-se por designar os estudantes em estágio, participantes deste estudo, de estagiários/terapeutas, considerando a condição objetiva de estagiário em formação profissional (KERN; LUZ, 2017).

Além disso, essa intersecção de papeis se manifestou nas falas dos participantes do estudo, quando se referem aos estagiários como terapeutas, embora com conhecimento e compreensão da condição e lugar de aprendizado e formação dos estagiários para a vida profissional.

Nesse espaço de estágio e considerando a condição de estagiário, é fundamental, no processo psicoterapêutico, construir a habilidade de constituir vínculo com os pacientes. Essa habilidade precisa ser lapidada desde a formação para que se alcance uma boa aliança 
terapêutica. Nessa relação, pacientes que conseguem estabelecer a transferência como instrumento terapêutico, a troca poderá ser trabalhada, e a transferência, reeditada com o novo terapeuta (FERREIRA, 2003).

De outra parte, aspectos sobre as experiências de rompimento de vínculos significativos, vividos pelo paciente, devem ser levados em consideração, pois dificultam a formação da aliança terapêutica e causam maior risco de abandono da terapia (BENETTI; CUNHA, 2008). As clínicas-escola devem tomar cuidado por contar com estagiários/terapeutas ainda em formação, que possuem um tempo determinado com seus pacientes (FERREIRA, 2003), pois os problemas com o terapeuta ou com a instituição, é o maior motivo de abandono ou desistência da psicoterapia, segundo Sei e Colavin (2016).

Existem características clínicas por meio das quais se pode se avaliar a qualidade das relações objetais dos pacientes, tais como: padrão de relações interpessoais significativas em sua vida; capacidade de estabilidade, gratificação e mutualidade; capacidade de estabelecer relações de troca ou apenas relações em que aguarda gratificação; independência ou necessidade de controle nas relações em virtude do medo de ser abandonado, perda ou ansiedade de separação; capacidade de envolver-se de forma efetiva e marcante; ser honesto; capacidade de expressar sentimentos e resolver os conflitos, quando surgem; manter relações interpessoais pautadas por sentimentos sustentados e perfil das pessoas com quem predominantemente se envolve e mantém relações de amizade (CORDIOLI; GREVET, 2018).

Cordiolo e Grevet (2018) ressaltam que é necessário que o terapeuta reúna determinadas características para que se estabeleça um bom vínculo. As qualidades do terapeuta possibilitam que o paciente se sinta acolhido, aceito e compreendido, não importando quais sejam suas dificuldades e conflitos a serem expostos. É preciso haver um mínimo de idealização e de impressão positiva prévia para o trabalho terapêutico, havendo ambiente continente.

Dentre as características do terapeuta, destaca-se a disponibilidade de tempo, suficiente para que o paciente possa expor seus problemas o mais livremente possível em um ambiente de privacidade e os motivos pelos quais buscou tratamento. Não emitir julgamentos, juízos ou conclusão antecipadamente; integridade e honestidade na comunicação; empatia, cordialidade, sensibilidade para sanar dúvidas e perguntas iniciais; 
tranquilidade para manter o equilíbrio independente dos conteúdos (CORDIOLI; GREVET, 2018).

O tratamento psicoterápico ocorre entre paciente e terapeuta e, dessa forma, uma boa relação terapêutica é fundamental para a qualidade da terapia. São elementos constituidores da relação psicoterápica, o vínculo e a aliança terapêutica, que por sua vez, dependerão da qualidade das relações objetais dos pacientes. A relação terapêutica vai se intensificando à medida que os objetivos do tratamento vão sendo estabelecidos e se comece a alcançar êxito na superação das primeiras dificuldades. Um bom vínculo entre terapeuta e paciente é fundamental para que haja uma boa aliança terapêutica (CORDIOLI; GREVET, 2018).

Embora não haja consenso em relação ao conceito de aliança terapêutica, é de entendimento comum sua importância no tratamento, e que pode influenciar, no resultado das psicoterapias, assim como no rompimento prematuro desse vínculo. A aliança terapêutica é essencial em todos os modelos de psicoterapia, estabelecida nas primeiras sessões é capaz de impactar positivamente o tratamento. Assim os pacientes com maior capacidade para ver seus terapeutas como hábeis a compreender seu ponto de vista e seu sofrimento, obtêm maior redução da sintomatologia; e os pacientes com maior habilidade de aliança, possuem melhores resultados na psicoterapia (MARCOLINO; IACOPONI, 2003). A aliança depende não somente do paciente e do terapeuta, mas também do enquadre (GOMES, 2003).

Assim como o vínculo, é possível analisar clinicamente a capacidade do paciente, estabelecer uma boa aliança terapêutica por meio de aspectos como a condição de estabelecer um boa conesão afetiva com o terapeuta; expectativas em relação à terapia e resolução de seus problemas por meio do processo psicoterápico; possuir flexibilidade psicológica; comprometimento em cumprir com o contrato psicoterápico; aderência às tarefas terapêuticas propostas pelo modelo específico de terapia (CORDIOLI; GREVET, 2018).

É prudente ter atenção especial às trocas no período inicial de tratamento, uma vez que a aliança terapêutica deve ser preservada como fator essencial para o sucesso da psicoterapia, o que, em clínicas-escola, fica prejudicado pela própria natureza desse espaço. É fundamental entender quais os aspectos que podem dificultar o desenvolvimento, assim como a manutenção e a ruptura da aliança, prevenindo um possível abandono do tratamento (OLIVEIRA; BENETTI, 2015). 
A troca do terapeuta durante a psicoterapia, portanto, irá incidir diretamente na aliança de trabalho, porém, poucos estudos explicam a forma como os pacientes vivem essa experiência e sua influência no processo psicoterápico. Nesse sentido, é preciso considerar as características institucionais dos serviços que convivem com a transitoriedade de terapeutas, como é o caso das clínicas-escola com os estagiários/terapeutas.

Para a compreensão desse fenômeno, buscou-se como base conceitos do campo psicoterapêutico comuns entre as diferentes teorias psicoterápicas, entendendo psicoterapia como termo que abarca conceituações de múltiplas modalidades de tratamento psicoterápico (ZIMERMAN, 2016).

Contudo, conceitos estritos à psicanálise foram utilizados, fundamentalmente, para contribuir no entendimento de determinados fenômenos da relação psicoterapêutica que emergiram ao longo da pesquisa.Também, pelo fato de ter-se tornado referência para práticas psicoterapêuticas posteriores, assim como por integrar os currículos de graduação em Psicologia (NICARETTA, 2011). Nicaretta esclarece, ainda, que modelos de psicoterapia foram influenciados pelo fazer clínico próprio da psicanálise, além de guardarem afinidades e terem funcionamento semelhante.

\section{MÉTODO}

Este estudo buscou compreender a vivência de pacientes na troca de estagiário/terapeuta de uma clínica-escola do sul do Brasil, durante o processo terapêutico e os significados atribuídos a essa experiência. O caminho metodológico adotado foi o da fenomenologia-hermenêutica, escolhido por se constituir um método qualitativo de pesquisa, adequado para se compreender experiências vividas e desvelar significados.

\section{PARTICIPANTES}

Foram investigados dois participantes escolhidos por sorteio, após indicação da coordenação da clínica-escola. Foi estabelecido como critério de inclusão ter vivenciado, pelo menos uma vez, nos últimos dois anos, a troca de estagiário/terapeuta no processo terapêutico. 


\section{ASPECTOS ÉTICOS}

O projeto foi submetido ao Comitê de Ética em Pesquisa e aprovada sua execução sob o parecer no. 225.751. Os objetivos do estudo e as questões éticas foram detalhadas antes das entrevistas, assim como a possibilidade de desistência em qualquer momento do estudo, sem qualquer prejuízo às participantes.

\section{PROCEDIMENTOS DE COLETA E ANÁLISE DE DADOS}

Para coleta de dados foi utilizada a entrevista em profundidade, realizada individualmente, pelos pesquisadores, em três momentos distintos (SEIDMAN, 2019). Cada encontro durou, em média, uma hora, e foi garantido sigilo sobre a identidade das participantes e proteção de interferências externas.

Todas as entrevistas foram gravadas, com autorização prévia, para que não se perdessem elementos das falas e houvesse melhor interação entre pesquisador e pesquisado.

A primeira entrevista teve como objetivo conhecer a trajetória de vida, à luz do tema do estudo. A segunda, levou as entrevistadas a reconstruir pormenores das experiências vividas dentro do contexto em que ocorreram, concentrando-se em detalhes concretos da troca terapêutica. Na terceira, as participantes foram convidadas a refletir sobre o significado atribuído a essa experiência.

Para análise e interpretação do material coletado tudo foi transcrito após cada encontro. O desafio foi dar sentido aos dados, reduzir o volume de informações e construir uma estrutura para alcançar o cerne das experiências vividas (PATTON, 2002), expressa no texto fenomenológico

A estrutura de significado foi obtida pelo entendimento do fenômeno descrito em termos de unidades de significado e temas (VAN MANEN, 2018). Essa composição das experiências foram os temas fenomenológicos que emergiram das unidades de significado, definidoras da essência da experiência de cada uma das participantes, encontrada nas transcrições de conversações gravadas, nos materiais das entrevistas e nas reflexões sobre os protocolos gerados (VAN MANEN, 2018). 


\section{RESULTADOS E DISCUSSÃO - TRAJETÓRIA DE ANA E MARIA}

Ana, nascida na zona rural, Ana tem 37 anos, é casada, mãe de dois filhos adolescentes e dona de casa. Acredita que seu nascimento não foi planejado por seus pais. Possuía dificuldade de relacionar-se com os familiares, segundo ela, por ser ciumenta e acreditar que os pais tinham preferência pela irmã. O pai trabalhava "no mato" e recebia auxílio dos filhos para descascar madeira. No período escolar tinha uma única amiga e conta que depois que casou perdeu esse contato. Aos doze anos deixou a escola para trabalhar, queria sair de perto da família, em virtude do ciúme que sentia da irmã e dos conflitos com os pais. Conheceu seu marido em um baile, quando tinha quatorze e ele dezesseis anos. Durante o namoro engravidou, e por desejo dos pais do namorado e de sua mãe, casou, apesar de não desejar. O segundo filho, aos oito meses, foi diagnosticado com déficit intelectual. A partir de então, conta que deixou de ter vida própria, voltando atenção quase que totalmente para o tratamento e cuidado desse filho.

Maria, 55 anos, é casada e mãe de uma filha. Sua mãe trabalhava em uma fábrica e o pai não possuía profissão certa, fazia frete com charrete e plantava vegetais. Moravam em um chalé com dois quartos. A relação entre os irmãos sempre foi muito boa. Duas professoras propuseram adotar Maria, que se negou por não querer sair de perto da mãe. 0 pai sempre exerceu um rígido controle sobre os filhos, exigindo que fossem exemplos. Na infância e adolescência possuía poucas amizades, porque o pai não permitia que se aproximasse de outras pessoas, frequentou apenas a escola e a casa de duas vizinhas. Teve seu primeiro emprego aos 14 anos, em um cartório, no qual trabalhou por 10 anos. Aos 21 anos engravidou do seu namorado, com quem casou após 10 anos de namoro.

\section{SIGNIFICADOS DAS EXPERIÊNCIAS VIVIDAS}

A partir das unidades de significado reveladas nos relatos, foi possível extrair a estrutura da experiência vivida por elas. Nesse processo, emergiram duas unidades de significado: características do estagiário/terapeuta, e aliança empática, que são a estrutura do tema fenomenológico - o paciente como sujeito no processo psicoterápico. Esse tema 
representa a essência do fenômeno vivido pelas participantes, em relação à troca de estagiário/terapeuta.

\section{CARACTERÍSTICAS DO ESTAGIÁRIO/TERAPEUTA}

As características do estagiário/terapeuta são fundamentais para configurar o modo de vinculação do paciente. O terapeuta precisa ter atenção integral, interesse na escuta, capacidade de compreender o paciente de forma ampla e empatia para sanar as dúvidas iniciais (CORDIOLI; GREVET, 2018). Caso não haja fatores como vínculo, tarefa e objetivos, possivelmente haverá falhas em algum dos componentes da aliança terapêutica, ocasionando rupturas na relação (CAMPEZATTO; SERRALTA; HABIGZANG, 2017). Essas características do estagiário/terapeuta são destacadas nas falas dos sujeitos:

Eu acho que o jeito da pessoa trabalhar contigo. Tem gente que nasceu para aquilo e tem gente que está se aperfeiçoando. Tem gente que tem aquela profissão no sangue, não tem dúvida. Isso foi o que aconteceu com o primeiro eu acho, ele viu a minha dificuldade (Ana).

Há profissionais e profissionais. Eu achava que ele não falava muito comigo, só eu falava. Ai eu pensei: será que isso vai me ajudar se só eu falo? Quando eu peguei o segundo já foi diferente [...]. Eu fui tão surpreendida! Aquela pessoa tão alegre, já começou a conversar comigo e a explicar como eu devia agir e tentar procurar outro jeito para ficar melhor [...] aí eu comecei a gostar mais (Maria).

Conforme expressam, as características dos estagiários/terapeutas influenciaram no vínculo e na aliança terapêutica. A configuração vincular para a formação de uma sólida aliança foi proporcional às características percebidas pelas pacientes. Ana relata a capacidade de compreensão do primeiro estagiário/terapeuta. Por outro lado, Maria não teve a mesma percepção em sua primeira experiência. Somente com o segundo estagiário/terapeuta encontrou empatia e continência para suas angústias. As características identificadas por Ana na primeira experiência e Maria na segunda podem ser observadas nos seus relatos:

Eu percebi que o primeiro arriscava mais comigo, ele não precisava fazer como o segundo que anotava para depois saber o que poderia me dizer. 0 primeiro falava o que achava, o que ele estava olhando em mim e o que estava enxergando. Ele não pensava duas vezes antes de dizer, ousava mais. O segundo, eu acho que tinha medo de falar alguma coisa que não fosse apropriada. Eu ficava esperando o que ele ia me trazer (Ana). 
Eu sempre saía aliviada, porque botava os problemas para fora, ele escutava muito bem, mas de me dar opinião, o primeiro nunca. Com o primeiro achei que fiquei na mesma etapa, no mesmo estágio em que entrei aqui. Não me ajudo [...] eu esperava escutar, mas nunca escutei isso, como agora eu escuto. Era isso que eu queria ouvir, essa ajuda (Maria).

As pacientes levavam demandas específicas para serem trabalhadas em terapia, porém, na perspectiva de Maria, o primeiro estagiário/terapeuta não conseguiu ser suficientemente continente para acolher suas angústias, assim como Ana se sentiu acolhida no processo. É preciso haver, por parte do paciente, um mínimo de idealização e de impressão positiva prévia em relação ao terapeuta, para que a aliança terapêutica se estabeleça, mesmo havendo um ambiente continente (CORDIOLI; GREVET, 2018).

A princípio ele ficou um pouco apreensivo com as coisas que eu contei, do jeito que eu era. Ele não sabia muito bem a resposta, eu sentia que ele não sabia muito bem o que iria me dizer, mas depois estudava o caso eu acho, fazia anotações e perguntava para supervisora dele [...] depois ele me trazia e expressava da maneira dele (Ana).

Com o primeiro eu não me senti acolhida como eu esperava. Quando vim para cá, com o primeiro, não foi assim o que eu esperava, mas depois com o segundo, com o terceiro, com o quarto que eu tô agora, foi maravilhoso (Maria).

Apesar de a configuração vincular de Maria com o primeiro estagiário/terapeuta ser diferente da construída com o segundo, a troca em si parece não ter influenciado de forma prejudicial o novo vínculo. Maria afirma ter se beneficiado com a troca, em razão das características do segundo terapeuta. Quando o terapeuta não consegue ser continente, o vínculo estabelecido é mais afetivo do que terapêutico, pois as pacientes não trabalham seus conteúdos, mas somente manifestam aflições:

Quando eu cheguei no primeiro eu estava bem ruim e ele me ajudou a melhorar bastante. Foi isso que me marcou, e o segundo o que foi importante, é que quando eu precisei ele estava ali para me escutar, era a pessoa que eu tinha e eu estava bem à vontade para falar o que eu quisesse (Ana).

Ganhos com o primeiro terapeuta não foram muitos, só que consegui tirar um pouco aquele peso que trazia [...]. Com o primeiro não foi muito grande [...]. Me aliviava, sim, porque eu tinha com quem falar. Com o segundo, na primeira vez a gente se conheceu e foi mais um conhecimento, já senti a diferença (Maria). 
As experiências de Ana e Maria revelam não ser a troca em si prejudicial ao processo terapêutico do paciente, apesar de sentirem a quebra do vínculo. Nos casos em que o paciente não possui uma boa aliança, a troca pode ser positiva, pois possibilita que encontre no novo estagiário/terapeuta as qualidades necessárias para sentir-se seguro, de modo a flexibilizar seu mecanismo defensivo e trabalhar seus conteúdos:

Acho que a troca de terapeuta não prejudicou. Não é cômodo, mas não prejudicou, não é algo que chegou a me prejudicar (Ana). Eu senti mais confiança com ele. Eu falei coisas que com o outro nunca tinha falado, com ele veio coisas lá do fundo do baú (Maria).

Outro fator manifestado nas falas é que a troca de terapeuta, por si só, não leva à desistência por parte do paciente, mas, sim, a falta de determinadas características do estagiário/terapeuta para garantir um bom vínculo terapêutico. A troca só será prejudicial quando o paciente for muito regressivo e não possuir condições psíquicas que a suportem (FERREIRA, 2003). Na experiência de Maria, a troca proporcionou a continuidade da psicoterapia:

Nunca pensei em parar. Agora que estou me achando melhor eu cogitei, mas não pensei de minha livre e espontânea vontade, quero ver se é possível, se eles acham que é necessário, não quero eu me dar alta. Quero que eles analisem e vejam se eu tenho essa possibilidade (Ana).

Ele não falava muito, ele queria que só eu falasse. Não sei se era o jeito dele, não sei. Eu conversava, contava as coisas assim, mas ele [...]. Às vezes, eu não sentia nem vontade de ir, porque eu pensava assim, se só eu vou lá falar, vou entrar no banheiro e começar a fala [...] eu fiquei meio assim, achando que não adiantava ir, porque não estava me ajudando muito [...]. Eu já não queria, já não estava mais com vontade de ir, vou ir lá e só eu vou falar, então vou pro meu quarto e falo sozinha (Maria).

Estou bem assistida e até melhor que se eu tivesse em um consultório pagando, eu me sinto muito bem, não vou sair [...] nunca pensei em parar por causa das trocas, não pensei mesmo. Não é pelo fato de pagar ou não pagar, é porque eu me sinto bem lá, então eu vou continuar lá [...]. Se tivesse continuado com o mesmo eu nem teria vindo mais (Maria).

Quando há troca de terapeuta, deve-se levar em consideração a personalidade do paciente (FERREIRA, 2003). No caso de Ana, foi possível estabelecer transferência com o novo 
estagiário/terapeuta. Nessas situações, o paciente possui condições para trabalhar a troca, e a transferência ser retomada, reeditada com o novo psicoterapeuta como ocorreu com Ana e Maria.

Um dos principais fundamentos para configurar o modo como o paciente irá vincularse ao terapeuta, são os antigos modelos objetais introjetados (ZIMERMAN, 2010), mesmo que em psicoterapia breve, caso da clínica-escola, não seja estimulada a transferência regressiva. A habilidade e dedicação do terapeuta é que poderão proporcionar a construção de um novo relacionamento objetal realista (CORDIOLI; GREVET, 2018).

\section{ALIANÇA EMPÁTICA}

Ana e Maria explicitam, em diversos momentos, uma aliança terapêutica bem constituída, na medida em que se apropriaram de seus compromissos com o processo terapêutico e com os papéis no contrato estabelecido.

Eu não estava tendo tempo para ir na terapia, e pedi se havia como passar para 15 dias porque eu não tinha mesmo. Algumas vezes ele marcava terapia, e acontecia de marcarem cirurgia para o meu filho, então não dava para eu vir e ligava para ele. Eu tinha o celular dele (Ana).

Para eu faltar só se tiver alguma coisa relacionada com a minha saúde, eu ligo e aviso um dia antes. Porque como a gente não gosta que deem o bolo na gente, a gente também não vai dar. Ele vinha de outra cidade, só para me atender, então eu acho que cooperei bastante (Maria).

Não é somente por suas necessidades que a paciente não deixa de comparecer aos atendimentos, mas, também, pelo contrato estabelecido com o estagiário/terapeuta, mesmo que não haja forte aliança. As pacientes assumem suas responsabilidades, têm comprometimento com o contrato psicoterápico:

A gente remarcava, ele foi bem acessível comigo, foi bem compreensivo. Ir na terapia é um compromisso. Como é que ele iria e eu não? Acho um descaso. Aconteceu de eu esquecer o dia e não ir, eu ficava para morrer quando acontecia isso (Ana).

Às vezes eu saia daqui 'bem jururu'. Mas eu vinha porque eu sou muito persistente, se fui encaminhada para ali é porque eu preciso, porque jamais irão tirar o tempo de outra pessoa que precisa de horário para me colocar ali. Sempre vinha, mas tinha umas sextas que eu pensava, será que eu vou? Vai ser diferente, mas não era (Maria). 
Do mesmo modo que a aliança terapêutica influencia na qualidade da psicoterapia, também terá impactos sobre a troca de estagiário/terapeuta, podendo tornar o processo menos angustiante para o paciente se for adequadamente trabalhado (MARCOLINO; IACOPONI, 2003).

É tudo programado, quando eu vou fazer a troca, ele já diz que vai se formar e passar para outro terapeuta. Então não me incomoda, mas se eu chegasse aqui, hoje, e tu não viesse, eu ia ficar totalmente desorganizada, porque havia programado vir aqui hoje. É uma coisa que acontece, mas depois eu fico assim totalmente desorganizada (Ana).

É legal a gente saber desde o início que vai ter uma troca, porque ser surpreendido com uma troca sem saber [...]. Então a gente não fica naquele desespero. O brabo seria eu estar contigo seis meses, um ano, e aí quando vê ele resolve ir para cidade dele. Ai eu fico sempre pensando que eu queria que ele estivesse aqui (Maria).

Além dos objetivos terapêuticos a serem atingidos, as participantes demonstraram conhecer a realidade da clínica-escola, compreendendo a transitoriedade de seus estagiários/terapeutas e o momento de aprendizado que vivenciam. A aliança terapêutica é distinta da constituída com terapeutas formados. No caso de estagiários/terapeutas, o vínculo que a estabelece é colaborativo, mais simétrica no sentido do terapeuta auxiliar o paciente em seus processos psíquicos e o paciente contribuir na formação do estagiário/terapeuta.

Eles precisam nos estudar e nós precisamos melhorar, então um ajuda o outro. Eu acho que é assim que a gente tem que pensar... A gente tem que entender que eles tão aqui estudando e nos ajudando, e a gente tem que aceitar numa boa e tentar ajudar eles também. Porque são seres humanos que nem nós, têm problemas que nem nós, então não vejo nenhuma dificuldade (Maria).

Eu fico com pena, porque é uma coisa que estava evoluindo, estava sendo bom, acho que tanto para mim quanto para eles que estão se formando, então é meio engraçado os sentimentos que se misturam [...]. Disse para ele que tivesse uma boa formatura e que fosse bem feliz (Ana).

Mesmo sentindo a troca, as participantes são empáticas e ficam gratificadas por terem contribuído com a formação dos estagiários/terapeutas, pois entendem a condição temporária na clínica-escola. Os vínculos, e por consequência, a aliança terapêutica é perpassada pelas normas e condicionantes da clínica-escola, denominado como vínculo transubjetivo (ZIMERMAN, 2010). O fato de o paciente saber, antecipadamente, que há um 
tempo determinado para o término, colabora para não haver fantasias regressivas onipotentes de união permanente com o terapeuta.

Sendo assim, a configuração vincular com o próximo estagiário/terapeuta receberá a influência da experiência de ter participado do processo de aprendizagem do psicólogo, fato que também pode esclarecer a postura mais ativa das pacientes após a troca, pois ambos estão aprendendo conjuntamente os papéis de paciente/terapeuta. A vivência de Ana e Maria na primeira experiência terapêutica marca, não só a especificidade daquele momento, mas também o período de espera pelo recomeço da terapia, e a relação com o novo estagiário/terapeuta.

\section{O PACIENTE COMO SUJEITO DO PROCESSSO TERAPÊUTICO}

A psicoterapia tem por objetivo proporcionar que o sujeito consiga apreender não utilizando modelos estereotipados em suas vivências. Em psicoterapia breve o paciente é visto como sujeito que possui uma interrupção do processo de aprendizagem, considerando a neurose como causadora (SIMON, 1990). Simon (1990) aponta que o terapeuta assume uma posição ativa, de quem possui o conhecimento, decide o fluxo da psicoterapia. Por sua vez, o paciente adota um papel passivo, daquele que não conhece e precisa ser conduzido.

Porém, percebe-se que a experiência das participantes, após a troca de estagiário/terapeuta, não corresponde a esse modelo:

Ele estava me conhecendo, a partir da segunda sessão já encerra aquela parte da pessoa te conhecer. Eu já havia relatado tudo que tinha passado e comento alguma coisa da terapia passada, é normal assim. Depende de mim, como eu falo as coisas, como eu exponho, e ele fica esperando eu concluir, o que me incomoda, até ele entender aquilo que se passa (Ana).

Se a pessoa não quiser conversar, eu vou falar para ela, agora eu já teria coragem de falar. Claro eu estava chegando, não ia dizer o caminho a seguir, que eu preciso disso [...]. Porque no início eu pensava que era assim, nunca tinha feito, mas depois quando veio o segundo e eu disse, ah é bem diferente (Maria).

As participantes sentem-se tão responsáveis quanto os estagiários/terapeutas pela terapia. De certa forma, elas direcionam e indicam o foco do tratamento para o novo estagiário/terapeuta. Tornam-se, portanto, mais ativas no processo terapêutico, por conhecer 
melhor a dinâmica da psicoterapia, e pela melhora de suas condições psíquicas, como se percebe nas falas:

Não houve período de adaptação com o segundo, foi direto. Não foi da mesma forma que o primeiro, porque eu já havia melhorado um pouco, já não estava tão problemática como com o primeiro [...]. Com o primeiro eu me adaptei na terceira semana, com o segundo já me senti a vontade com ele, porque já sabia o que eu iria trabalhar. Não é como a primeira vez que não sabia o que me esperava ali, o que iria acontecer (Ana).

Eu estou me sentindo. Estou tendo capacidade para falar para ele, coragem vamos dizer. Porque até então eu tinha ficado quietinha, era minha primeira vez, nunca tinha passado por nenhum psicólogo a não ser lá no hospital (Maria).

A atitude ativa adotada por Ana após a troca de estagiário/terapeuta vai ao encontro das explicações de Simon (1990). Segundo Simon, uma das principais particularidades da psicoterapia breve é o menor e delimitado tempo de tratamento, e para tanto, o terapeuta precisa planejar e saber conduzir o paciente em psicoterapia, ou seja, se colocar de forma diretiva no processo. As experiências contrapõem o que Simon apresenta, na medida em que as participantes manifestam que, de alguma forma, colaboram na condução do processo:

Eu tenho ajuda do psicólogo, do psiquiatra, e eu tenho que me ajudar, porque se eu não me ajudar, ninguém vai me ajudar (Maria).

Acho que é mais conforme o paciente leva as coisas que ele consegue definir como vai te ajudar. Chegar ali e dizer que está bem, eles não vão ter o que ajudar [...]. O meu papel na troca é facilitar como ele vai direcionar a terapia, é esse o meu papel (Ana).

Podemos perceber que Ana e Maria modificam a postura e papel após a troca, característica referente à psicoterapia breve, na qual tanto paciente como terapeuta elegem um foco e não há relação hierárquica, mas, sim, o estímulo à colaboração, parceria e maior simetria (BRAIER, 2008). Braier lembra que a psicoterapia breve é um misto de apoio, busca por insight e reforço de ego, levando a crer que as participantes, após a primeira experiência terapêutica, estavam psiquicamente melhor estruturadas, conseguindo identificar o foco do tratamento:

O primeiro foi descascando. Ele ia indagando para saber o que eu ia largar para ele, o que iria falar para ver o que realmente estava incomodando. Eu não sabia por onde ele ia começar, acho que tudo me incomodava [...]. Quando tive que voltar eu consegui passar um pouco o que tinha feito antes da terapia, o que tinha contado para o outro, para ele saber o que iria precisar trabalhar, para ele saber mais ou menos (Ana). 
Eu comecei a enxergar mais longe. Mudei muito o meu comportamento, porque era meio estourada. Me encanto comigo mesma, o que eu mudei desde que eu vim para cá. Comecei a vir aqui, comecei a falar, comecei a receber conselhos e as direções (Maria).

O objetivo da psicoterapia deve ser de livre escolha do terapeuta e do paciente, podendo mudar no curso da experiência, se ambos assim o desejarem, e entender que se faça necessário (SIMON, 1990). Na ocasião da troca, Ana e Maria apresentaram reduzidas manifestações de ansiedade, característica de muitos pacientes quando iniciam a psicoterapia. Pode-se perceber que após uma primeira vivência terapêutica, mesmo que de curta duração, alcançaram condições de pensar e refletir sobre suas vidas e experiências, mesmo no caso de Maria que não construiu uma boa aliança terapêutica com seu primeiro estagiário/terapeuta.

\section{CONSIDERAÇÕES FINAIS}

A partir das experiências de troca de estagiário/terapeuta, emergiram duas unidades de significado: as características do estagiário/terapeuta e a aliança empática. Essas unidades deram estrutura ao tema fenomenológico: o paciente como sujeito no processo psicoterápico.

As características do psicólogo são fundamentais para configurar o modo como o paciente irá vincular-se, no processo psicoterápico. Influenciarão o vínculo e a aliança terapêutica, de forma que quanto mais capacidade empática, atenção integral, tranquilidade para manter o equilíbrio, independente dos conteúdos trazidos e empatia para sanar as dúvidas iniciais o terapeuta possuir, melhor será a configuração vincular para a formação de uma sólida aliança terapêutica.

Os estagiários/terapeutas precisam conseguir acolher, aceitar e compreender 0 paciente, não importando tanto se antes ou após a troca, pois, a mudança em si parece não ter influenciado de forma necessariamente prejudicial o novo vínculo. Foi a capacidade ou incapacidade do estagiário/terapeuta ser continente, no processo terapêutico, o mais significativo, desenvolvendo vínculos mais afetivos ou mais terapêuticos. Importante salientar que a troca de terapeuta não causou a desistência da terapia.

Apesar de perceberem a quebra de vínculo, não houve prejuízo no processo terapêutico. Quando não houve uma boa aliança terapêutica, a troca foi positiva, pois 
possibilitou que encontrassem no novo estagiário/terapeuta as qualidades necessárias para que pudessem sentir-se em segurança, de modo a flexibilizar mecanismos defensivos e trabalhar angústias e ansiedades.

As participantes demonstram conhecer a realidade da clínica-escola, compreendendo a transitoriedade de seus terapeutas e o momento de aprendizado que vivenciavam. Os achados indicam que um contrato terapêutico claro e bem construído, e a forma como as participantes se apropriaram de seus papéis no contrato estabelecido, minimizam drasticamente as angústias que poderiam surgir no processo de troca. Houve um forte compromisso com a terapia e com o estagiário/terapeuta.

A aliança terapêutica, portanto, é diferente da constituída com terapeutas formados, pois o vínculo que a estabelece é colaborativo, no sentido do terapeuta auxiliar o paciente em seus processos psíquicos e o paciente contribuir na formação do terapeuta. Mesmo sentindo a troca, Ana e Maria foram empáticas e sentiram-se gratificadas por terem contribuído com os terapeutas em formação, permitindo inferir que a aliança terapêutica, nesse caso, é perpassada pelas normas e contexto da clínica-escola.

As participantes sentiam-se tão responsáveis quanto os terapeutas pela terapia após a troca. São elas que, de certa forma, direcionavam e indicavam o foco do tratamento para o novo estagiário/terapeuta. Manifestaram que precisavam orientar o caminho para o novo terapeuta, colaborando na condução de um processo mais simétrico após a troca. Tornaramse mais ativas no processo da nova experiência terapêutica, por conhecer a dinâmica da psicoterapia, e pela melhora de suas condições psíquicas.

Não havia uma relação hierárquica, mas, sim, o estímulo à colaboração e parceria, pois as pacientes já estavam psiquicamente melhor estruturadas, conseguindo identificar o foco do tratamento. Percebe-se que após uma primeira vivência terapêutica, mesmo que de curta duração, alcançam condições para pensar e refletir sobre suas vidas e experiências, mesmo quando não houve uma forte aliança terapêutica anterior.

\section{REFERÊNCIAS}

BENETTI, S. P. C.; CUNHA, T. R. S. Abandono de tratamento psicoterápico: implicações para a prática clínica. Arquivos Brasileiros de Psicologia, v. 60, n. 2, 2008, p.p. 48-59. 
BRAIER, E.A. Psicoterapia breve de orientação analítica. 4. ed. São Paulo: Martins Fonte, 2008.

BRASIL. Lei n.11.788, de 25 de setembro de 2008. Dispõe sobre o estágio de estudantes. Disponível em: http://www.planalto.gov.br/ccivil 03/ ato2007-2010/2008/lei/l11788.htm. Acesso em: 24 jun. 2020.

CAMPEZATTO, P. V. M. P.; SERRALTA, F.B.; HABIGZANG, L. F. Fatores envolvidos na interrupção de uma psicoterapia psicanalítica com uma paciente borderline: um estudo de caso sistêmico. Ciências Psicológicas, v. 11, n. 1, 2017, p.p. 7-17.

CORDIOLI, A. V.; GREVET, E. H. Psicoterapias: abordagens atuais. 4. ed. Porto Alegre: Artmed, 2018.

FERREIRA, M.C. A troca de terapeutas nos atendimentos psicanalíticos em instituições. Estudos de Psicologia, v. 20, n. 2, 2003, p.p. 63-69.

GOMES, F.G. A relação entre os mecanismos de defesa e a qualidade da aliança terapêutica em psicoterapia de orientação analítica de adultos: um estudo exploratório. Dissertação de Mestrado. Universidade Federal do Rio Grande do Sul, Porto Alegre, 2003.

KERN, C.A.R.; LUZ, A.K. A psicanálise no contexto da clínica escola. Revista de Ciências Humanas, v. 51, n. 1, 2017, p.p. 250-268.

MARCOLINO, J. A. M; IACOPONI, R. The early impacto $f$ therapeutic aliance in brief psychodynamic psychotherapy. Revista Brasileira de Psiquiatria, v. 25, n. 2, 2003, p.p. 78-86.

NICARETTA, M. A emergência da nova psicoterapia na Era de Ouro Estadunidense: o resumo de uma história. Boletim Academia Paulista de Psicologia, v. 31, n. 81, 2011, p.p. 358-377.

OLIVEIRA, N. H.; BENETTI, S. P. C. Therapeutic alliance: establishment, maintenance and disruption of relationship. Arquivos Brasileiros de Psicologia, v. 67, n. 3, 2015, p.p. 125-138.

PATTON, M. Q. Qualitative evaluation and research methods. London: Sage Publications, 2002.

SANTOS, A. C.; NOBREGA, D. O. Dores e Delícias em ser Estagiária: o estágio na formação em psicologia. Psicologia: ciência e profissão, v. 37, n. 2, 2017, p.p. 515-528.

SEI, M. B.; COLAVIN, J.R.P. Desistência e abandono da psicoterapia em um serviço-escola de Psicologia. Revista brasileira de psicoterapia, v. 18, n. 2, 2016, p.p. 37-49.

SEIDMAN, I. Interviewing as qualitative research: a guide for researchers in education and the social sciences. New York, NY: Teachers College Press, 2019.

SILVA, J. A. P.; COELHO, M. T. Á. D.; PONTES, S. A. Estágio supervisionado em psicologia clínica com orientação psicanalítica: uma revisão de literatura. Psicologia: teoria e pesquisa, v. 35, e35433, 2019. 
SIMON, R. Psicanálise e psicoterapia breve. Periódicos Eletrônicos de Psicologia. v. 1, n. 1, 1990, p.p. 93-96.

VAN MANEN, M. Researching lived experience: human science for an action sensitive pedagogy (2nd ed.). New York, NY: Left Coast Press, 2018.

ZIMERMAN, D. E. Os quatro vínculos: amor, ódio, conhecimento, reconhecimento na psicanálise e em nossas vidas. Porto Alegre: Artmed, 2010.

ZIMERMAN, D. E. Uma atualização da psicoterapia psicanalítica. Fórum Freudiano, v.7, n. 1, 2016, p.p. $14-27$.

Recebido em 22 de maio de 2020.

Aprovado em 21 de julho de 2020

(c) (1) (2) (2) 